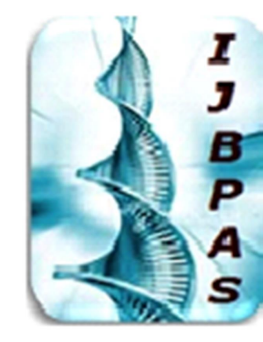

International Journal of Biology, Pharmacy and Allied Seiences (IJBPAS)

'A Bridge Betueen Caboratory med QRendo'

WwW.ijbpas.com

\title{
REGIONAL PATTERN OF MALARIA AND IDENTIFICATION OF HIGH RISK ZONES IN SONITPUR DISTRICT OF ASSAM
}

\section{SAMEER BARUAH}

Ph.D Scholar, Dept. of Geography, Rajiv Gandhi University, Arunachal Pradesh, India *Corresponding Author: Sameer Baruah; E Mail: sameer.baruah91@gmail.com Received $19^{\text {th }}$ July 2021; Revised $20^{\text {th }}$ Aug. 2021; Accepted $29^{\text {th }}$ Sept. 2021; Available online $1^{\text {st }}$ Nov. 2021

\section{https://doi.org/10.31032/IJBPAS/2021/10.11.1019}

\begin{abstract}
Malaria is one of the life-threatening diseases and it was known from the ancient time. Malaria was known to be a world-wide problem, but now it occurs in some specific areas especially in the tropical areas. Sonitpur district of Assam is associated with this fatal disease from time to time. The environmental factors of Sonitpur district are highly responsible for the occurrence of this particular disease. All the health blocks of the district are more or less affected by Malaria. Some regions are more vulnerable to this dangerous disease. Within the district, the frequency of Malaria is found to be variable, spatially as well as temporally. This paper aims to analyze the frequency of Malaria within the district from one region to another. The paper also aims to identify some high risk zones of Malaria in the district. This paper would be helpful to medical personnel and planners for preparing a suitable plan or policy to combat ever-increasing Malaria in the district.
\end{abstract}

\section{Keywords: Malaria, Spatio-Temporal Pattern, High Risk Zones, Sonitpur} \section{INTRODUCTION}

The word 'malaria' is a combination of two Indian words, i.e. 'mad' meaning bad and 'aria' meaning air. The name malaria was applied to the disease because in ancient time it was believed that the disease occurred due to inhalation of poisonous emanations from the ground surface, especially marshy land. Malaria has been considered as one of the life-threatening infections caused by Protozoan Parasite. It is still a foremost public health concern of most endemic patches of the world [1]. 
This dangerous infection is transmitted by female Anopheles mosquito that claims almost three people every four minutes [8].

Malaria was known to be a worldwide problem, but now it occurs in some specific areas especially in the tropical areas. In fact, malaria is restricted to some specific regions in its distribution. Malaria affects $36 \%$ of the world population in 107 countries and territories placed in the tropical and subtropical provinces. In the South-East Asian region, out of about 1.4 billion persons living in 11 countries, 1.2 billion $(85.7 \%)$ are visible to the risk of malaria, and most of them live in India [2].

Malaria is an intense ancient disease characterized by repeated attacks of fever. Malaria disease was said to be the most vital human health problem about 20 years ago and killed millions of people across the world. The economic loss from the malaria knew no bounds. After the Second World War, the incidence of malaria declined gradually. After 1945, the great discovery and use of D.D.T has reduced the incidence of malaria disease in most of the countries. With the effective use of D.D.T. malaria has been either controlled or eliminated from most of the countries.

Malaria is typically caused by Plasmodium parasite carried by the female Anopheles mosquito. Anopheles mosquitoes carry this Plasmodium parasite, and when these mosquitoes bite people the parasite is released into people's bloodstream. Once the parasites enter into bloodstream, the parasites travel to the liver where they get mature. After few days the mature parasites enter the bloodstream and starts infecting red blood cells. Within 2 or 3 days, the parasites in the blood cells multiply, leading to infected cells to burst open. The life cycle of the plasmodium protozoan includes three basic stages. The first stage occurs in the mosquito's body and the second and third stages take place in a person [6].

India has a long record of success and fights with Malaria control [5]. In 2018, an estimated 228 million cases of malaria occurred worldwide, compared to 251 million cases in2010. In India, a population of 126 million was at danger of malaria with an estimate of 6 million cases in 2018 [7]. In India, districts with $30 \%$ or more tribal population added to $46 \%$ of total Malaria cases and $47 \%$ Malaria deaths in the country [4].

In India, Malaria is found to be highly distributed in rural and tribal regions of Madhya Pradesh, Orissa, Maharashtra, Rajasthan, Jharkhand etc. Urban areas contribute about $15 \%$ of the total malaria cases reported in India and are primarily associated with construction activities and migrant population [3]. In Sonitpur area of 
Assam, incidence of Malaria has been found to be acute. The climatic conditions and geographical factors of the region contribute to the occurrence of such disease in the region since early times.

\section{MATERIALS \& METHODS}

In the study only secondary data are used. In order to collect relevant data many sources have been taken into consideration. Data concerned with spatial distribution of various diseases in the study area have been collected from the Office of the Health \& Family Welfare (IDSP), Sonitpur District, Assam. Moreover, books as well as journals related to Medical Geography are also taken for detail analytical study. In few cases, internet links have also been taken into consideration for further study. In order to prepare maps of disease distribution or risk zones, AutoCad map software has been used.

In the study, spatial distribution of Malaria disease has been proposed to be analyzed at the block level of the Sonitpur District. The study is carried out by taking seven health blocks with certain specific diseases. Analysis has been done with absolute data of incidence of diseases. The collected data have been systematically tabulated to show the temporal as well as spatial variation of the incidence of diseases in all the health blocks of the district. Taking into consideration of the above methods, the proposed study has been done in a proper way.

\section{RESULTS \& DISCUSSION}

The district of Sonitpur has been divided into seven health blocks, and all the health blocks are characterized by frequency of Malaria in different time periods. In the district, total number of malaria case diagnosed from 2011 to 2016 is $1,93,431$ in number. Among the health blocks of the district, the highest malaria cases are found in Dhekiajuli health block where the total incidence from 2011 to 2016 is $\mathbf{5 7 4 9 0}$, which is about $30 \%$ of the total malaria cases of the Sonitpur district. Dhekiajuli region is followed by North Jamuguri health block, accounts about 29\% of the total cases of the study area. Bihaguri health block ranks third in this regard with total cases of $33522(17.33 \%)$, which is followed by Balipara health block, Biswanath health block, Behali health block and Gohpur health block where the total cases of malaria disease from 2011 to 2016 are 21098 (10.91\%), 14235 (7.36\%), $10115(5.23 \%)$ and $1138 \quad(0.59 \%)$ respectively.

The temporal variation of Malaria incidence has been observed in the district. The incidence of malaria disease is not same within the health blocks of the district from 2011 to 2016. The incidence of 
malaria is highly fluctuating among the BPHCs from one year to another (Table 1).

From the Table 1, it has been found that the lowest incidence of malaria occured in Gohpur BPHC where total cases of malaria are 1138 from 2011 to 2016, which is very low compared to other health blocks of the district. It is worth mentioning that in 2016 there are only 18 malaria cases found to be occurring in Gohpur BPHC. The second lowest malaria incidence has been found in Behali health block where total incidence of malaria from 2011 to 2016 is $\mathbf{1 0 1 1 5}$ with year-wise variation of 1,834 (2011), 1,886 (2012), 1,576 (2013), 1,252 (2014), 1,771 (2015) and 1,796 (2016).

\section{High Risk Zones of Malaria}

From the analysis of the above facts, the study aims to understand the spatial variation of Malaria along with its vulnerable locations in the district. Some health blocks of the district are characterized by high incidence of Malaria, while some others are characterized by less number of the same. Based on this fact, the study has identified some high risk zones of Malaria in the district (Figure 1).

From the Figure 1, it has been cleared that Dhekiajuli and Bihaguri health blocks of the district are highly affected by Malaria, where incidence reached above 4000. North Jamuguri health blocks showed the incidence between 2000 and 4000, while other health blocks are characterized by the incidence below 2000 cases of Malaria. From these facts, Dhekiajuli and Bihaguri area of the district have been identified as high risk zones of Malaria, North Jamuguri area as moderate risk zone, and other health blocks have been identified as low risk zones of Malaria.

\begin{tabular}{|c|c|c|c|c|c|c|c|c|}
\hline \multirow[b]{2}{*}{ Year } & \multicolumn{7}{|c|}{ Table 1: Temporal and Spatial Distribution of Malaria Cases (in number) in Sonitpur, 2011-16 } & \multirow[b]{2}{*}{ Total } \\
\hline & $\begin{array}{c}\text { Gohpur } \\
\text { BPHC }\end{array}$ & $\begin{array}{l}\text { Behali } \\
\text { BPHC }\end{array}$ & $\begin{array}{l}\text { Biswanath } \\
\text { BPHC }\end{array}$ & $\begin{array}{c}\text { Jamuguri } \\
\text { BPHC }\end{array}$ & $\begin{array}{c}\text { Balipara } \\
\text { BPHC }\end{array}$ & $\begin{array}{c}\text { Bihaguri } \\
\text { BPHC }\end{array}$ & $\begin{array}{c}\text { Dhekiajuli } \\
\text { BPHC }\end{array}$ & \\
\hline \multirow{2}{*}{2011} & 647 & 1834 & 4194 & 15628 & 8072 & 7895 & 10064 & \multirow{2}{*}{48334} \\
\hline & $1.34 \%$ & $3.79 \%$ & $8.68 \%$ & $32.33 \%$ & $16.70 \%$ & $16.33 \%$ & $20.82 \%$ & \\
\hline \multirow{2}{*}{2012} & 99 & 1886 & 3188 & 13100 & 4863 & 6184 & 13314 & \multirow{2}{*}{42634} \\
\hline & $0.23 \%$ & $4.42 \%$ & $7.48 \%$ & $30.73 \%$ & $11.41 \%$ & $14.50 \%$ & $31.23 \%$ & \\
\hline \multirow{2}{*}{2013} & 22 & 1576 & 2270 & 11505 & 2490 & 5176 & 11988 & \multirow{2}{*}{35027} \\
\hline & $0.06 \%$ & $4.50 \%$ & $6.48 \%$ & $32.85 \%$ & $7.11 \%$ & $14.78 \%$ & $34.23 \%$ & \\
\hline \multirow{2}{*}{2014} & 121 & 1252 & 1873 & 9086 & 3053 & 4498 & 11458 & \multirow{2}{*}{31341} \\
\hline & $0.39 \%$ & $3.99 \%$ & $5.98 \%$ & $28.99 \%$ & $9.74 \%$ & $14.35 \%$ & $36.56 \%$ & \\
\hline \multirow{2}{*}{2015} & 231 & 1771 & 1484 & 3534 & 1336 & 4198 & 5657 & \multirow{2}{*}{18211} \\
\hline & $1.27 \%$ & $9.72 \%$ & $8.15 \%$ & $19.41 \%$ & $7.34 \%$ & $23.05 \%$ & $31.06 \%$ & \\
\hline \multirow{2}{*}{2016} & 18 & 1796 & 1226 & 2984 & 1283 & 5570 & 5007 & \multirow{2}{*}{17884} \\
\hline & $0.10 \%$ & $10.04 \%$ & $6.86 \%$ & $16.69 \%$ & $7.17 \%$ & $31.15 \%$ & $28.00 \%$ & \\
\hline \multirow[b]{2}{*}{ Total } & 1138 & 10115 & 14235 & 55839 & 21098 & 33522 & 57490 & \multirow{2}{*}{193431} \\
\hline & $0.59 \%$ & $5.23 \%$ & $7.36 \%$ & $28.87 \%$ & $10.91 \%$ & $17.33 \%$ & $29.72 \%$ & \\
\hline
\end{tabular}

Source: Office of the Health \& Family Welfare (IDSP), Sonitpur 


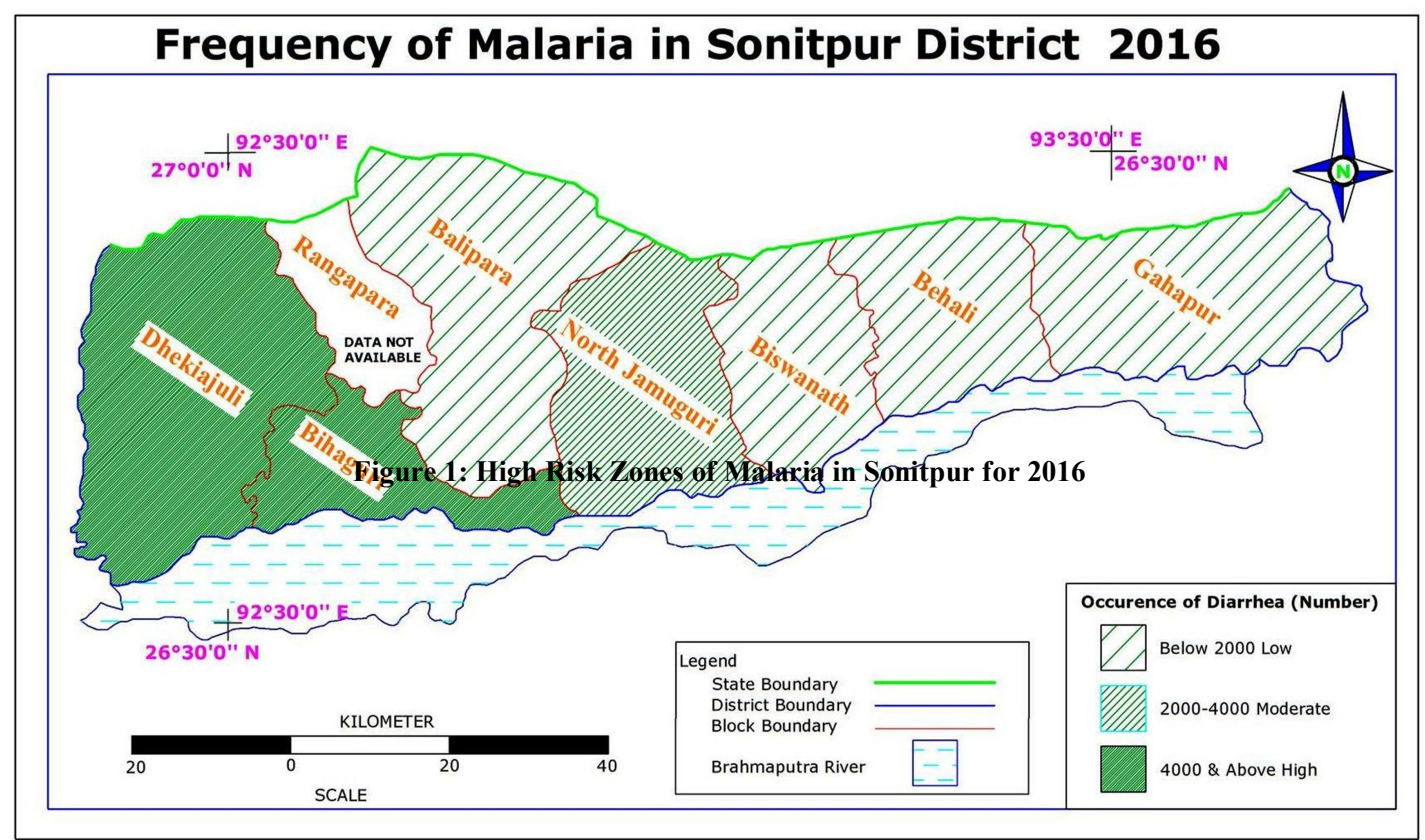

\section{CONCLUSION}

Malaria is seen to be more prominent in Dhekiajuli, North Jamuguri and Bihaguri BPHCs because in these regions the environment seems to be favorable for the generation of a lot of female Anopheles mosquitoes which are the main reasons of the occurrence of Malaria. Use of D.D.T. can reduce the incidence of Malaria, but in these regions use of D.D.T. seems to be very poor. This might be another reason for the occurrence of higher number of Malaria cases in these particular health blocks. On the other hand, Gohpur and Behali BPHCs are characterized by well environmental conditions that do not allow much generation of female Anopheles mosquitoes and hence, lowest number of Malaria incidences has been occurred in these two blocks. Use of
D.D.T. is also seems to be good, which might be another reason for the lowest number of Malaria incidence in these two particular health blocks.

Health care personnel are trying their best to reduce cases of Malaria in the district, but it is still threatening most of the people of the district. The elimination of Malaria needs some suitable approaches and strategies from the village level to the regional level. All people with confirmed cases must be advised to stay under mosquito net until parasite clearance to avoid community spread. Availability of drugs and essential Malaria commodities should be ensured for long term management of community Malaria.

\section{ACKNOWLEDGEMENT}

The present article is a part of my M. Phil Dissertation and hence, I would 
like to express my deep gratitude to my Research Supervisor Prof. Nishamani Kar, Department of Geography, Rajiv Gandhi University, Arunachal Pradesh for his constant support and help, encouragement and proper guidance, without which the current article would have not been possible. I am really thankful to Health and Family Welfare Department (IDSP), Sonitpur District for providing me required data related to various diseases and their spatial distribution in the district.

\section{REFERENCES}

[1] Geleta, G and Ketema, T, (2016), Severe Malaria Associated with Plasmodium falciparum and $P$. vivax among Children in Pawe Hospital, Northwest Ethiopia, Malaria Research and Treatment, Research Article, Hindawi Publishing corporation.

[2] Kondrachine A. V., (1992), Malaria in WHO Southeast Asia Region;Indian J. Malariol. 29 129-160.

[3] Kumar A, Valecha N, Jain T and Dash A P, (2007), Burden of Malariain India:
Retrospective and Prospective View; Am. J. Trop. Med.Hyg. 77 69-78.

[4] Sharma RK, Thakor HG, Saha KB, Sonal GS, Dhariwal AC,Singh N. (2015) Malaria situation in India with special reference totribal areas. Indian $\mathrm{J}$ Med Res. 141:537-41.

[5] Sharma V.P., (1996), Re-emergence of malaria in India. Ind J MedRes, 103:2645.

[6] The world book Encyclopedia (1994). World book international, World book inc. A scott fetzer company. London, Sydney, Tunbridge, Wells, Chicago, vol. 13. P.79.

[7] World Health Organization. World Malaria Report (2019), Available from: https://www.who.int/publicationsdetail/world-malaria-report-2019.Accessed December 7, 2019.

[8] World Malaria Report (2020), 20 years of global progress and challenges. Geneva: World Health Organization. 